\title{
A STUDY OF SOME OF THE PHYSIOLOGICAL EFFECTS OF SULFANILAMIDE. II. METHEMOGLOBIN FORMA- TION AND ITS CONTROL
}

\author{
By ALEXIS F. HARTMANN, ANNE M. PERLEY, AND HENRY L. BARNETT \\ (From the Department of Pediatrics, Washington University School of Medicine, and the \\ St. Louis Children's Hospital, St. Louis)
}

(Received for publication May 6, 1938)

One of the most commonly observed toxic effects of the administration of moderately large doses of sulfanilamide is the development of methemoglobinemia with resulting cyanosis and reduction in the oxygen carrying capacity of the blood. Sulphemoglobinemia also has been reported, and Marshall and Walzl (1) have postulated the presence of a black oxidation product of sulfanilamide which stains the red blood cells.

The chemical nature of methemoglobin and the conditions necessary for its formation are discussed in some detail by Peters and Van Slyke (2). A wide variety of agents may promote the formation of methemoglobin from reduced hemoglobin, but the chemical reaction taking place presumably always involves the oxidation of the ferrous iron, $\mathrm{Fe}$, in ordinary hemoglobin to the ferric iron, $\dot{F} \ddot{e}$, in methemoglobin. The exact manner in which sulfanilamide, or a by-product of sulfanilamide, promotes such an oxidation is still unknown. It is stated by Archer and Discombe (3) that it is highly probable that all drugs containing the group $\mathrm{C}_{6} \mathrm{H}_{5} \mathrm{~N}<$ are capable of causing methemoglobinemia and of facilitating the production of sulphemoglobin. In regard to the formation of the latter, Harrop and Waterfield (4) have shown, as pointed out particularly by Paton and Eaton (5), that while various aromatic compounds promote methemoglobinemia, when these compounds are given along with sulphur the result may be sulphemoglobinemia. The latter investigators feel that methemoglobin is the true toxic result of a large dose of sulfanilamide, or possibly of quite a moderate dose in an unusually susceptible person, and sulphemoglobin formation takes place only when sulphur compounds are available, as is the case when they are present in the bowel in unusually large amounts. Methemoglobinemia, therefore, can be considered the more direct result of sulf- anilamide administration, and in the cases which we are to report, by far the most important cause of the cyanosis.

The formation of methemoglobin is reversible, and the reconversion of methemoglobin to hemoglobin in the body takes place slowly, so that when the factor which is promoting excessive methemoglobin formation is withdrawn the methemoglobinemia gradually disappears. However, in patients receiving sulfanilamide, the factor contributing to methemoglobin production is present certainly as long as the drug is being given. As will be pointed out later, continued rapid reconversion of methemoglobin to hemoglobin may be desirable. This has been accomplished by the use of methylene blue.

Hauschild (6) in June 1937 reported upon the effectiveness of Katalysin (thionin) as an antidote for methemoglobinemia produced in animals by the injection of sodium nitrite, analine, nitrobenzol, and para-aminophenol. In investigations on cats and rabbits, he showed by quantitative estimation that after the methemoglobin concentration had risen to 40 to 50 per cent of the total pigment, the intravenous injection of thionin caused nearly all of it to be reconverted to hemoglobin within ten minutes. $\mathrm{He}$ feels that the action takes place by means of the reversible oxidation-reduction system of thionin-leucothionin, the system of hemoglobin-methemoglobin being shifted in favor of hemoglobin. In an earlier investigation (7), he reported the effectiveness of both thionin and methylene blue (tetramethyl-thionin- $\mathrm{HCl}$ ) as an antidote in methemoglobin poisoning, but at that time was in doubt as to the nature of the mechanism involved.

Wendel (8) in October 1937 proposed the use of methylene blue in the treatment of methemoglobinemia resulting from the administration of sulfanilamide. He was unable to produce methe- 
moglobinemia in dogs and rabbits by the administration of sulfanilamide, even in large doses, but observed that methylene blue given intravenously to animals poisoned with sodium nitrite greatly increased the rate of reconversion of methemoglobin to hemoglobin. $\mathrm{He}$ reported upon two of our children who were being treated with sulfanilamide, and in whom a single intravenous injection of $1 \mathrm{mgm}$. of methylene blue per kilogram of body weight reduced the methemoglobin from 20 to 18 per cent of the total pigment, respectively, to less than 3 per cent in 30 minutes. He pointed out that Williams and Challis in 1933 reported that methylene blue was an effective antidote for para-brom-analine poisoning, and that shortly afterwards, Steele and Spink used methylene blue in a case of analine poisoning and one of acetanilid poisoning with what they considered dramatic recoveries. Both groups of workers stated that the methemoglobinemia shown by their patients before the administration of methylene blue rapidly disappeared.

\section{METHODS}

In the studies to be reported, direct estimation of the amount of methemoglobin in the blood was made by a simple spectroscopic method devised by Wendel (personal communication). In this procedure, by properly diluting the unknown sample, the intensity of the methemoglobin absorption band is made to equal that of a standard which is prepared from a sample of the same blood by completely converting the hemoglobin to methemoglobin by the addition of potassium ferricyanide and diluting to a convenient working concentration. The amount of methemoglobin is then expressed as per cent of the total pigment. In a number of instances the amount of nonoxygen carrying hemoglobin was determined indirectly by the difference between the total hemoglobin present, as estimated by the acid hematin method of Sahli, and the functional hemoglobin as determined by the oxygen capacity (9), of the same sample of blood. The correlation between these two independent methods of determining the amount of hemoglobin incapable of combining with oxygen, as can be seen from Table $I$, is reasonably close, and the possible inaccuracies inherent in two of the three methods
TABLE I

Correlation between concentrations of methemoglobin and per cent of non-oxygen carrying hemoglobin

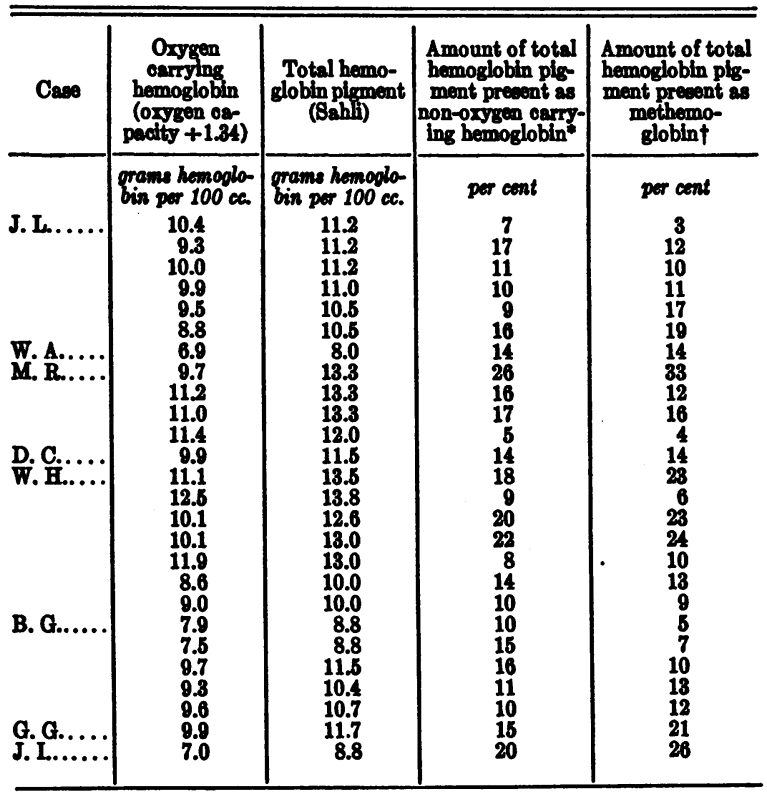

* As calculated from the equation:

Sahli hemoglobin - (oxygen capacity $\div 1.34$ ) $\times 100$. Sahli hemoglobin

$\dagger$ As determined directly by the spectroscopic method of Wendel.

employed are great enough to account for most of the discrepancies in the results. These data are included to show that, if spectroscopic examination of the blood of patients suspected of having methemoglobinemia from sulfanilamide therapy is not possible, determination of the oxygen capacity and of total pigment of the blood provides a reasonably reliable substitute, which is confirmatory of an opinion expressed in an earlier report of Basman and Perley (10).

The sulfanilamide concentration of the blood was determined by the method of Marshall (11).

\section{Methemoglobin accumulation}

Frequency of methemoglobin accumulation in human subjects following sulfanilamide administration. In almost every patient treated with sulfanilamide, in doses over 0.1 gram per $\mathrm{kgm}$. per 24 hours, we have observed some degree of cyanosis. This cyanosis is of a characteristic shade, and, after some experience, the observer can usually differentiate it from the usual type of cyanosis caused only by reduced hemoglobin. 
Coincidently, in every case in which cyanosis 'was observed and in which the blood of the patient was examined spectroscopically, we were able to detect the absorption band characteristic of methemoglobin.

Rate of methemoglobin accumulation following sulfanilamide administration. There is a marked individual variation in the rate at which methemoglobin accumulates following the administration of sulfanilamide, but the rate of accumulation in general depends upon the dose. With an initial large dose of sulfanilamide, equivalent to 0.15 to 0.2 gram per $\mathrm{kgm}$., given either orally or subcutaneously, clinically recognizable methemoglobin cyanosis usually becomes manifest in from 2 to 5 hours. In most cases this corresponds to a blood methemoglobin concentration of at least 10 per cent of the total pigment. In patients receiving 0.1 gram per $\mathrm{kgm}$. or less per 24 hours, clinical cyanosis, if it occurs at all, may not become evident until 2 or 3 days after the administration has been started. Table II shows the rate of accumulation in several patients receiving different amounts of sulfanilamide.

Relation of the degree of methemoglobin accumulation to the sulfanilamide concentration of the blood. While there seems to be some correlation between the sulfanilamide concentration of the blood and the degree of methemoglobinemia, as is seen from Figure 1, the degree of methemoglobin accumulation which occurs following sulfanilamide administration seems to depend more upon an individual characteristic than upon the sulfanilamide concentration. We have gained the clinical impression that the greater the toxicity of the patient and the more marked the

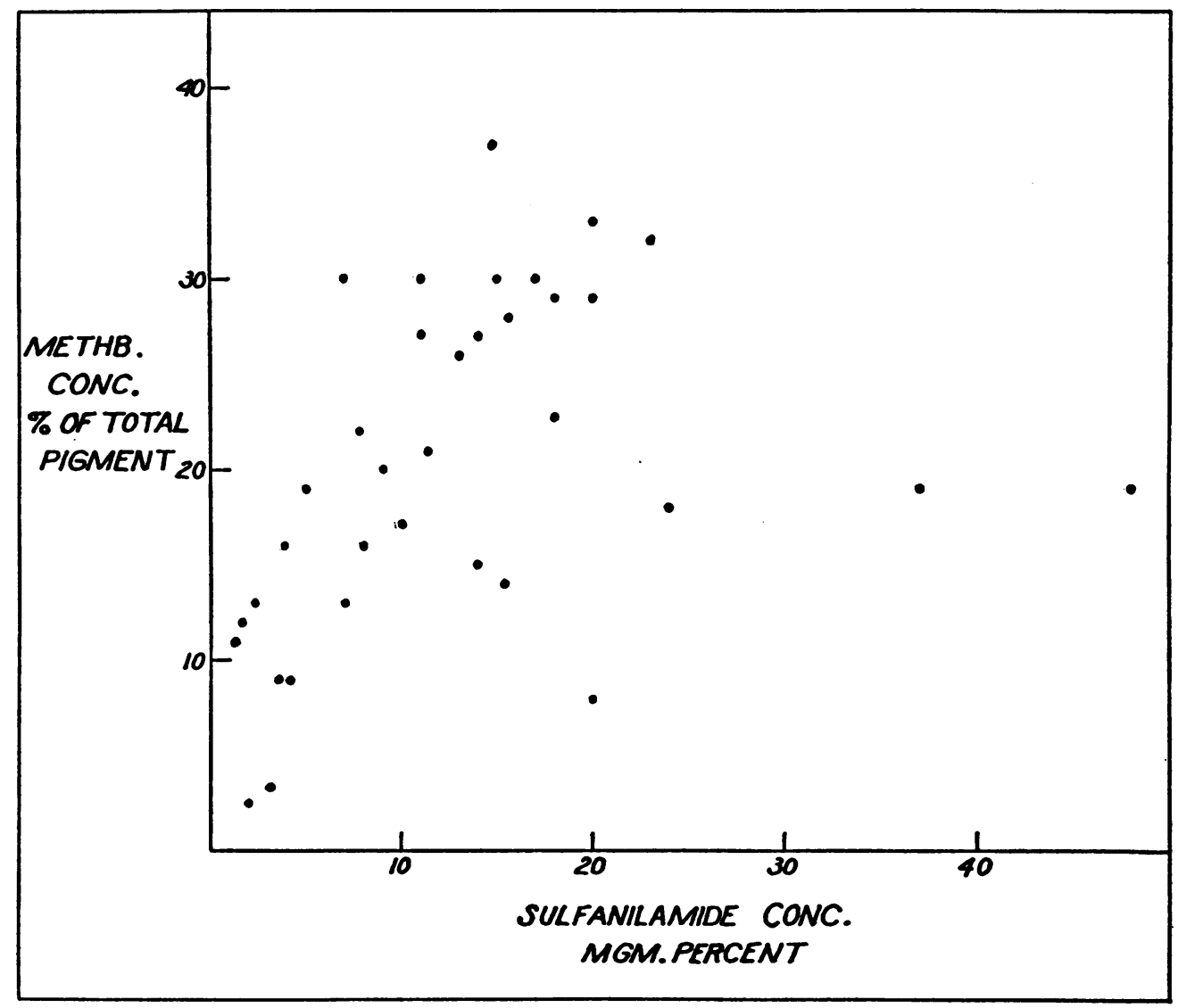

Fig. 1. General Correlation Between Sulfanilamide Concentration of Blood and DeGREE OF METHEMOGLOBINEMIA

Each dot represents the sulfanilamide and methemoglobin concentrations in a given sample of blood. 
TABLE II

Rate of accumulation of methemoglobin following sulfanilamide administration

\begin{tabular}{|c|c|c|c|c|}
\hline Case & Bulfanilamide administration & $\begin{array}{l}\text { Time } \\
\text { after } \\
\text { starting } \\
\text { aulfanil } \\
\text { amido }\end{array}$ & $\begin{array}{l}\text { Methemo- } \\
\text { globin oon- } \\
\text { centration }\end{array}$ & $\begin{array}{l}\text { Bul- } \\
\text { fanil- } \\
\text { amide } \\
\text { concean- } \\
\text { tration }\end{array}$ \\
\hline J. L.... & $\begin{array}{l}0.2 \text { gram per kgm. as Initilal dose, fol } \\
\text { lowed by } 0.2 \text { gram per kgm. per } 24 \\
\text { hours in } 6 \text { divided doses; after } 48 \\
\text { hours Increased to } 0.4 \text { gram per } \\
\text { kgm., and after } 72 \text { hours to } 0.6 \text { gram }\end{array}$ & $\begin{array}{l}45 \text { minutes } \\
5 \text { hours } \\
71 \text { hours } \\
84 \text { hours }\end{array}$ & $\begin{array}{c}\text { per cent of } \\
\text { total } \\
\text { pigment } \\
3 \\
12 \\
17 \\
10\end{array}$ & $\begin{array}{c}\text { mom. } \\
\text { per cont } \\
\\
21.7 \\
38.8 \\
\mathbf{4 8 . 2}\end{array}$ \\
\hline $\begin{array}{l}\text { J. L... } \\
\text { H. B.... } \\
\text { D. G... }\end{array}$ & $\begin{array}{l}0.2 \text { gram per } \mathrm{kgm} \text {, as initial dose, fol- } \\
\text { lowed by } 0.2 \text { gram per kgm. per } 24 \\
\text { hour in } 6 \text { dividod doess. } \\
0.2 \text { gram per } \mathrm{kgm} \text {. In } 6 \text { divided doses. } \\
0.1 \text { gram per kgm. per } 24 \text { hours in } 6 \\
\text { divided doees. } \\
0.1 \text { gram per kgm. per } 24 \text { hours in } 6 \\
\text { divided doses. }\end{array}$ & $\begin{array}{l}61 \text { hours } \\
12 \text { hours } \\
20 \text { hours } \\
14 \text { hours } \\
26 \text { hours } \\
1 \text { day } \\
2 \text { days } \\
4 \text { days } \\
6 \text { days } \\
12 \text { hours } \\
2 \text { days } \\
4 \text { days } \\
5 \text { days } \\
6 \text { days }\end{array}$ & $\begin{array}{r}12 \\
10 \\
11 \\
15 \\
27 \\
6 \\
9 \\
15 \\
13 \\
3 \\
5 \\
9 \\
9 \\
9\end{array}$ & \begin{tabular}{r|}
21.7 \\
17.6 \\
17.9 \\
14.0 \\
17.0 \\
7.7 \\
10.6 \\
14.1 \\
8.9 \\
2.2 \\
8.4 \\
3.8 \\
4.3
\end{tabular} \\
\hline
\end{tabular}

acute inflammatory process, the greater the tendency for methemoglobin accumulation. Four of the five patients in whom methemoglobin concentrations were above 30 per cent of the total pigment, with sulfanilamide concentrations of the blood below $20 \mathrm{mgm}$. per cent, were extremely ill, having severe infections and high fevers. In a given individual, however, there does seem to be better correlation between sulfanilamide and methemoglobin concentrations, as can be seen from Table II and Figure 2.

\section{Rate of reconversion of methemoglobin to hemoglobin}

After withdrazual of sulfanilamide. The methemoglobin accumulating as a result of the administration of sulfanilamide is slowly reconverted to hemoglobin following withdrawal of the drug. The fall roughly parallels the decrease in the sulfanilamide concentration of the blood, requiring usually from 24 to 72 hours, depending upon the concentrations of the two reached prior to the withdrawal of sulfanilamide (Figure 2).

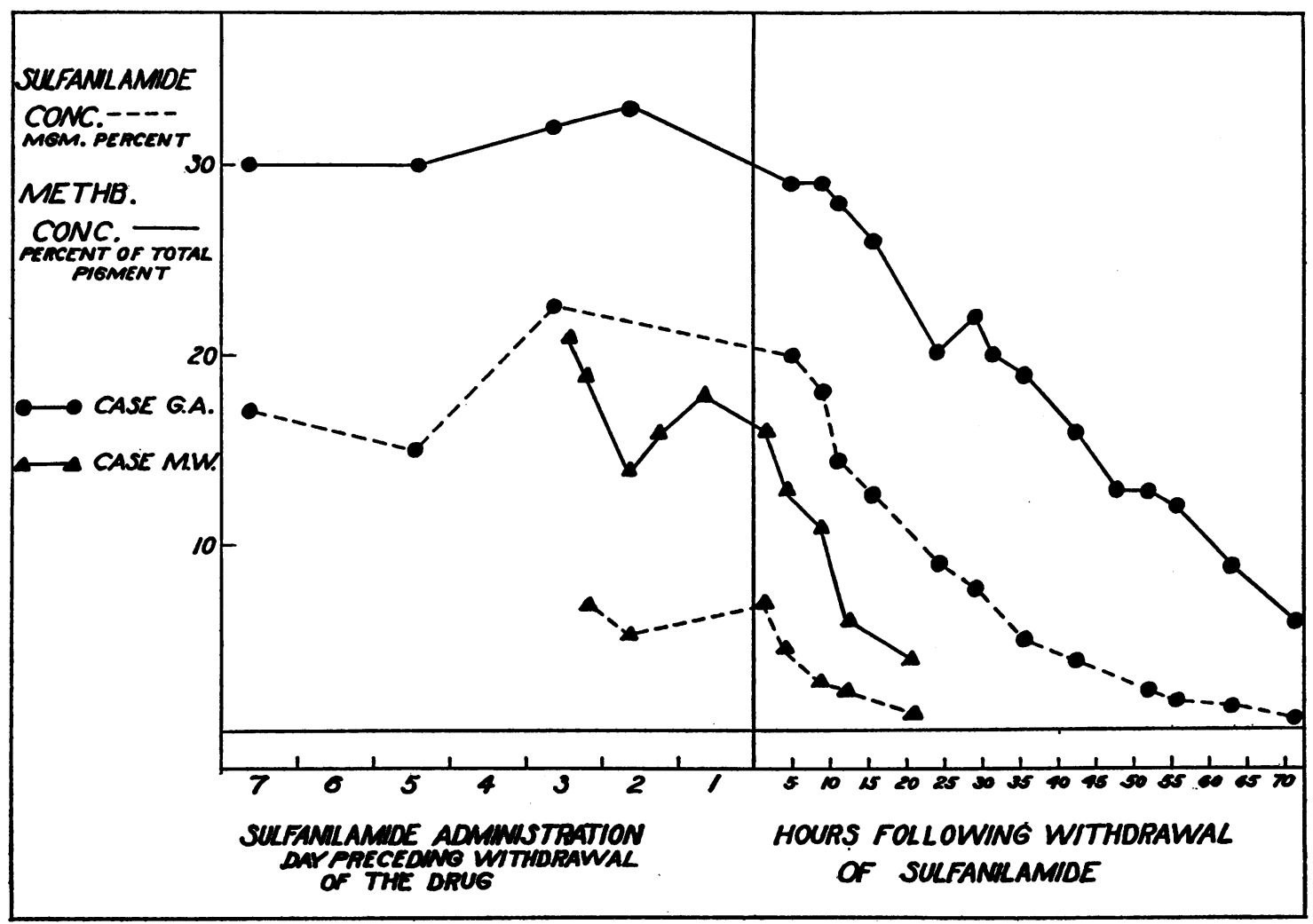

Fig. 2. Correlation Between Sulfanmamide Concentration of Blood and Degree of Methemoglobinemia in Individual Cases, Showing Particularly the Rate of Disappearance of Methemoglobin After the Discontinuation of Sulfanilamide. 
Following the intravenous injection of methylene blue with continued sulfanilamide administration. The use of methylene blue for the control of severe methemoglobinemia was begun by us at the suggestion of Wendel. At first, the dye was administered intravenously as a one per cent solution, the dosage being from 1 to $1.5 \mathrm{mgm}$. of methylene blue per kgm. of body weight. The effectiveness of this dosage in reducing the methemoglobinemia is shown in Figure 3 . The decrease or complete disappearance of cyanosis observed simultaneously with the fall in methemoglobin in the blood is quite spectacular, especially when the original cyanosis was intense. The effect is practically complete within $30 \mathrm{~min}$ utes. Figure 3 also demonstrates that following its reduction, methemoglobin reaccumulates at a rapid rate.

After the oral administration of methylene blue with continued administration of sulfanilamide. Again at the suggestion of Wendel, we undertook to control the accumulation of methemoglobin by the oral administration of methylene blue. The dose usually employed was one or two grains (65 or $130 \mathrm{mgm}$.) every 4 hours, depend- ing upon both the size of the patient and the dose of sulfanilamide given. Figures 4 to 9 demonstrate the effectiveness of this method of administration.

\section{PROTOCOLS}

Case 1. Donald B., a 41/2-year-old white boy, weighing $14.5 \mathrm{kgm}$., was admitted to the hospital with bilateral mastoiditis which required operation. After the patient had received approximately 0.2 gram of sulfanilamide per $\mathrm{kgm}$. per 24 hours for 6 days, the methemoglobin concentration was found to be 16 per cent of the total pigment, and the blood sulfanilamide $7.9 \mathrm{mgm}$. per cent. With the same dose of sulfanilamide continued, the patient was given one grain of methylene blue five times daily at 4-hour intervals. Ten hours after the administration of the first dose of methylene blue there was noted a definite fall in the methemoglobin concentration to 4 per cent. A low level was maintained throughout the following 6 days of observation. The blood sulfanilamide concentration ranged between 7.4 and 10.9 mgm. per cent during this period.

In this small child it is apparent that with the administration of 0.2 gram of sulfanilamide per $\mathrm{kgm}$. of body weight per 24 hours, there was considerable accumulation of methemoglobin which, however, was well controlled by the administration of only one grain of methylene blue 5 times a day.

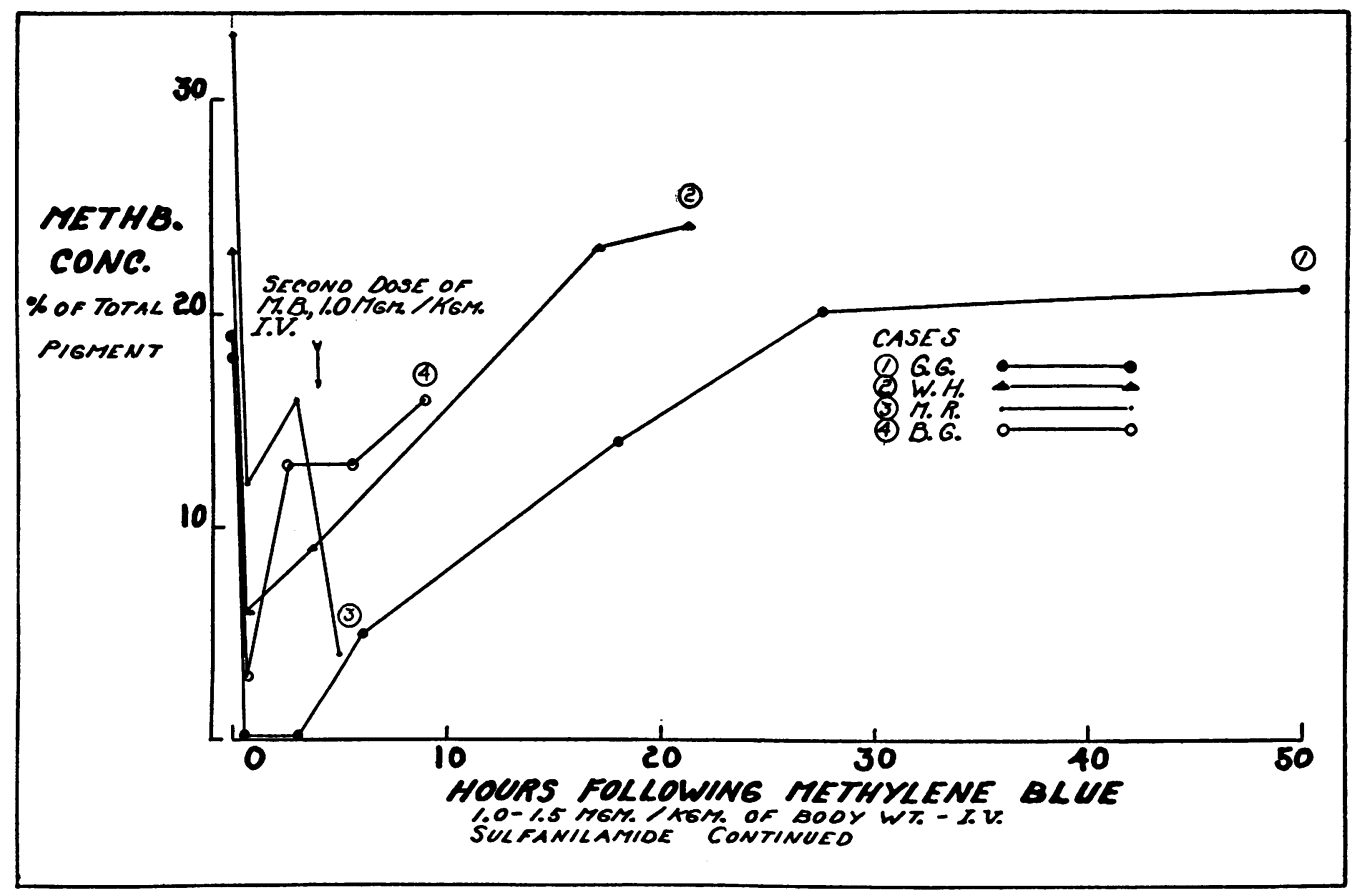

Fig. 3. Rapid Reduction of Methemoglobinemia Following the Intravenous Administration of Methylene Blue, and Rate of Methemoglobin Reaccumulation 


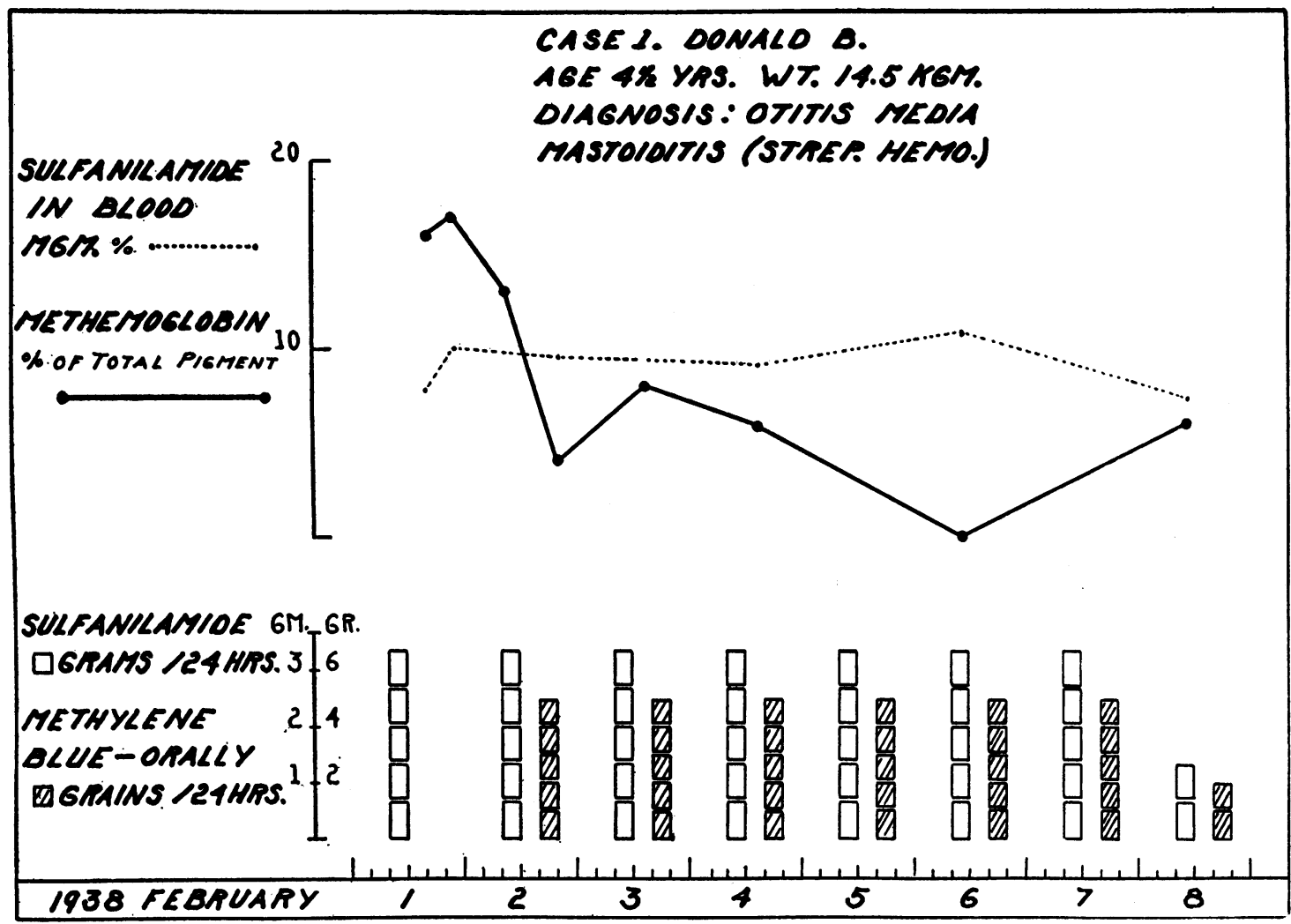

Fig. 4. Reduction of Methemoglobinemia After Oral Administration of Methylene Blue

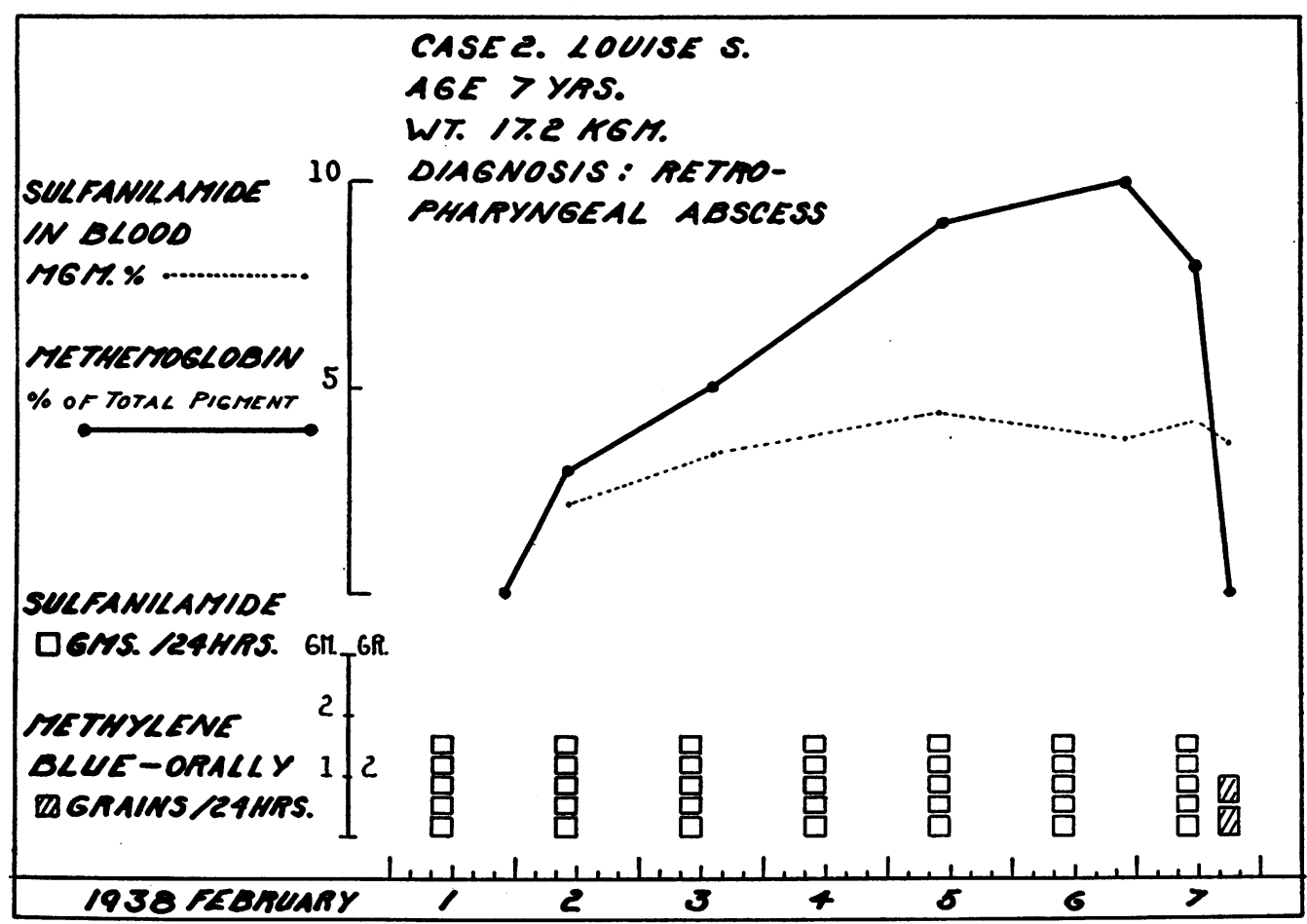

Fig. 5. Rapid Disappearance of Slight Methemoglobinemia After Oral Administration of Methylene Blue 


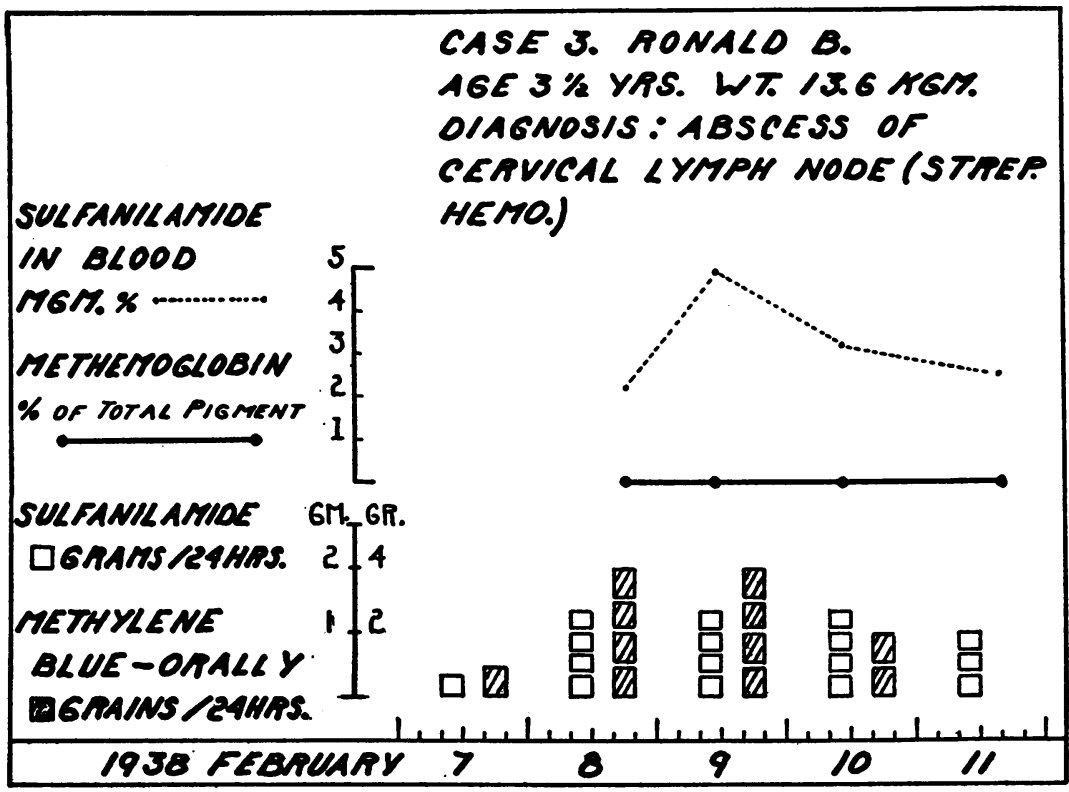

Fig. 6. Prevention of Accumulation of Methemoglobin by Oral Administration of Methylene Blue

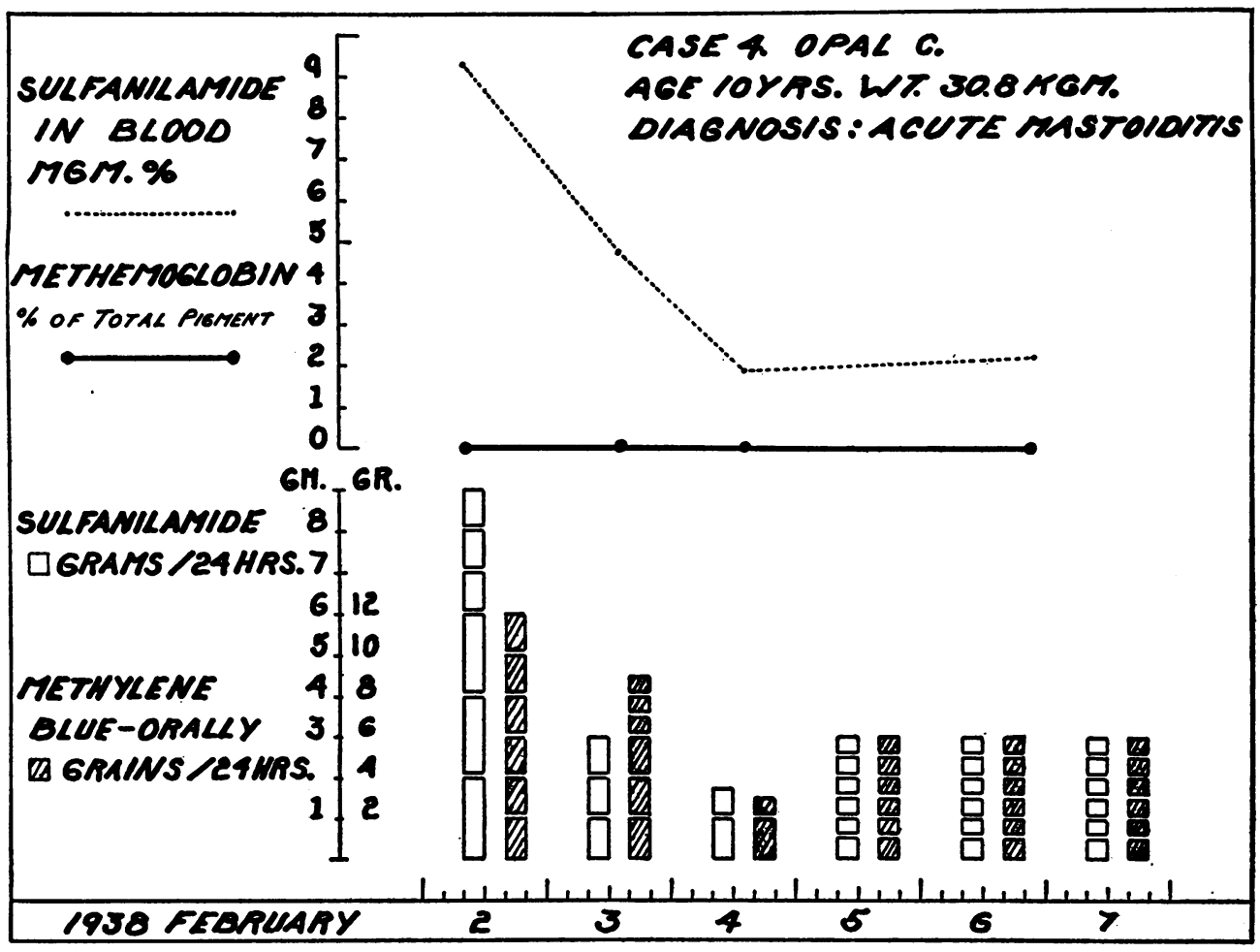

Fig. 7. Effectiveness of Oral Administration of Methylene Blue in Preventing Accumulation of Methemoglobin Following Large Initial Dose of Sulfanilamide 


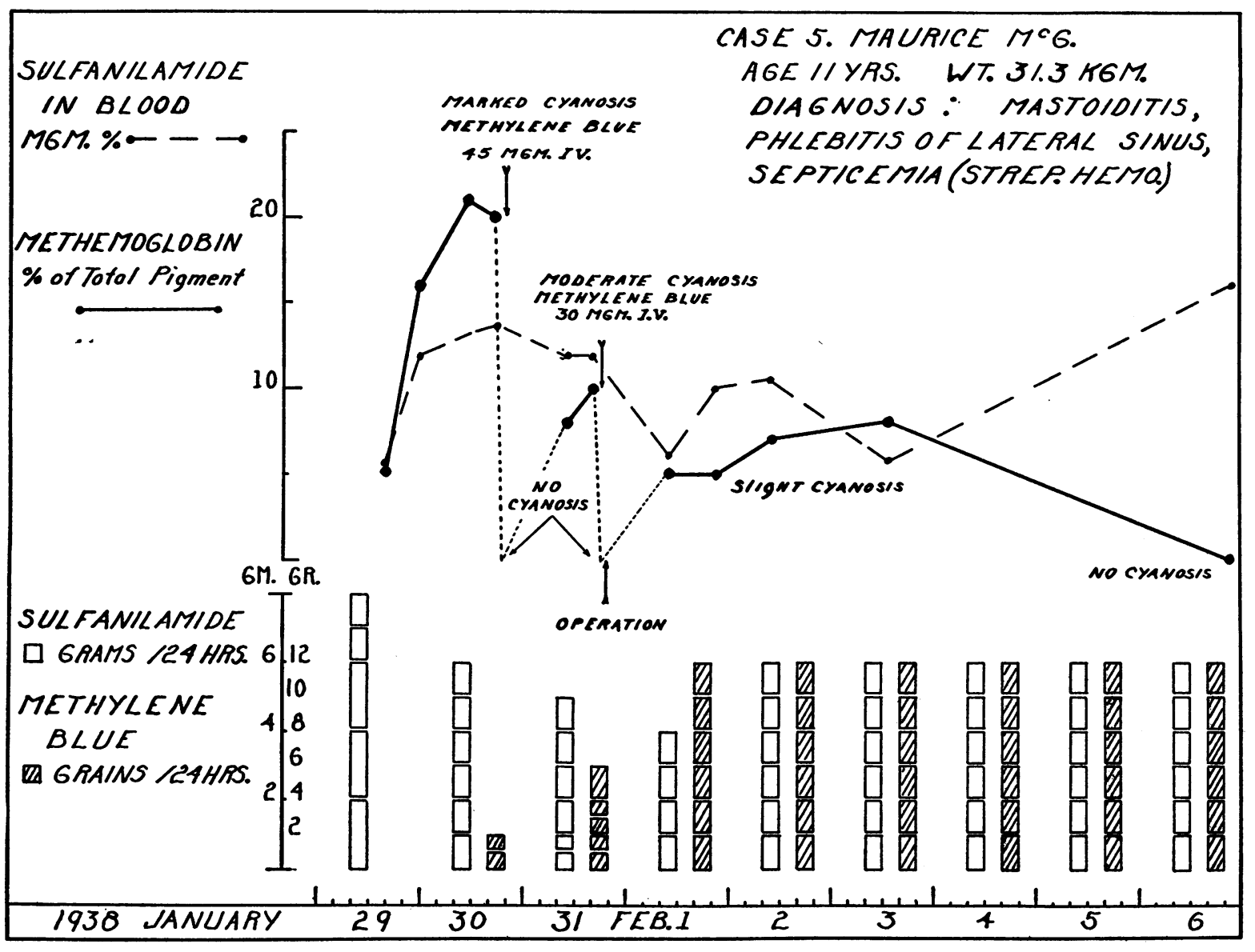

Fig. 8. Reduction of Methemoglobinemia by Intravenous Administration of Methylene Blue. Recurrence with Inadequate Oral Administration, and Subsequent Better Control by Increased Dose

Case 2. Louise S., a 7-year-old white girl, weighing $17.2 \mathrm{kgm}$. , was admittted to the hospital with a diagnosis of retropharyngeal abscess. She was given 0.1 gram of sulfanilamide per $\mathrm{kgm}$. per 24 hours, and methemoglobin was allowed to accumulate for a period of 6 days, during which time its concentration slowly rose to a level of 10 per cent of the total pigment. On the seventh day, the administration of one grain of methylene blue every 4 hours, along with the sulfanilamide, was started. Only one subsequent determination of methemoglobin was made, 5 hours after the administration of methylene blue was begun, and at this time no methemoglobin band was detected.

It is apparent that this patient developed a relatively small amount of methemoglobin with the administration of 0.1 gram of sulfanilamide per $\mathrm{kgm}$. per 24 hours, and 2 doses only of methylene blue, one grain each, were sufficient to cause disappearance of the methemoglobin band.

Case 3. Ronald B., a 31/2-yeár-old white boy, weighing $13.6 \mathrm{kgm}$., was admitted to the hospital because of postscarlatinal cervical adenitis. The administration of ap- proximately 0.1 gram of sulfanilamide per $\mathrm{kgm}$. per 24 hours and one grain of methylene blue every 6 hours was begun immediately, and on 3 subsequent days examination of the blood revealed no methemoglobin band, with the sulfanilamide concentration of the blood ranging from 2.2 to $4.9 \mathrm{mgm}$. per cent. The methylene blue was discontinued on the fourth day, and the patient was discharged 24 hours later, by which time no methemoglobin had yet accumulated.

This case demonstrates the prevention of the accumulation of any detectable amount of methemoglobin by the administration of one grain of methylene blue every 6 hours when 0.1 gram of sulfanilamide per $\mathrm{kgm}$. per 24 hours was being given.

Case 4. Opal C., a 10-year-old white girl, weighing $30.8 \mathrm{kgm}$., was admitted to the hospital on February 1, 1938, acutely ill with mastoiditis and associated cellulitis. The following day, February 2, 1938, she was given an initial dose of sulfanilamide, $0.2 \mathrm{gram}$ per $\mathrm{kgm}$. in 3 divided doses, between 10:00 a.m. and 12:00 noon. With each dose of sulfanilamide she received 2 grains of methylene blue. Following this initial dose, she was 


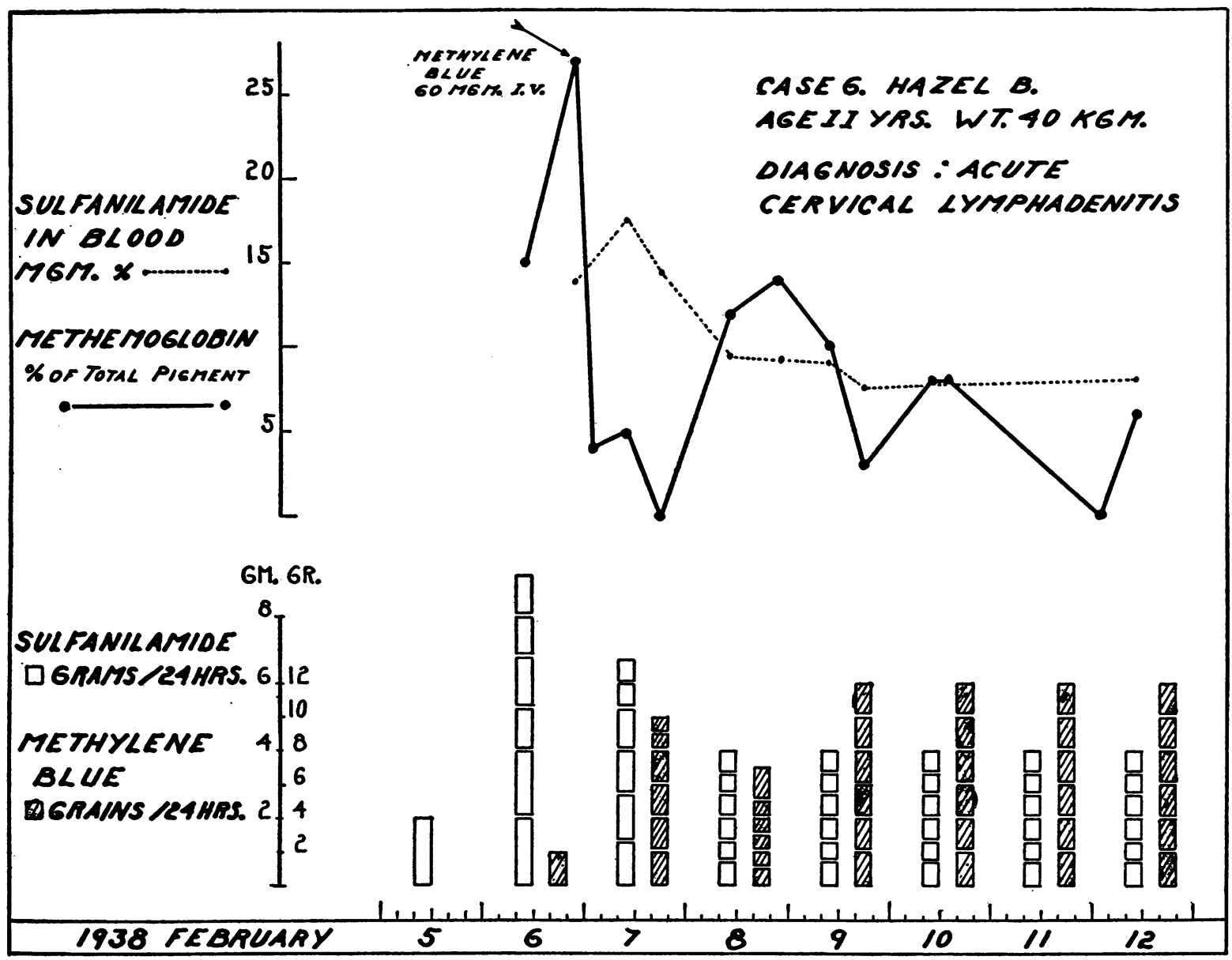

Fig. 9. Marked Methemoglobinemia Eliminated by Intravenous Injection of Methylene Blue and Controlled by Oral Administration. Reaccumulation of Methemoglobin with Doses of Sulfanilamide and Methylene Blue Proportionately Reduced; Later Control with Increased Methylene Blue.

given 0.2 gram of sulfanilamide per $\mathrm{kgm}$. per 24 hours and 2 grains of methylene blue every 4 hours through 12:00 noon on February 3, 1938, at which time the sulfanilamide was discontinued because of vomiting which was thought to be caused by the administration of the drug. However, because a mastoidectomy was to be performed the next morning, the methylene blue was continued in one-half its former dose to prevent any accumulation of methemoglobin. One dose of sulfanilamide and one of methylene blue were then given 4 hours before operation, since a high sulfanilamide concentration of the blood seemed desirable at the time of operation. Both drugs were discontinued for 16 hours after operation, following which they were again administered in approximately one-half of their former amounts. No accumulation of methemoglobin was detected throughout the period of observation.

This case demonstrates the prevention of methemoglobin accumulation in a patient receiving a large initial dose of sulfanilamide by administering a correspondingly large dose of methylene blue. Subsequent accumulation of methemoglobin was prevented by the administration of 2 grains of methylene blue every 4 hours during the period when she was receiving 0.2 gram of sulfanilamide per kgm. per 24 hours.

Case 5. Maurice McG., an 11-year-old white boy, weighing $31.3 \mathrm{kgm}$., was admitted to the hospital with mastoiditis and lateral sinus phlebitis. He was given an initial dose of sulfanilamide of 0.2 gram per kilogram in 2 hours in 3 divided doses, and thereafter received 0.2 gram per $\mathrm{kgm}$. in 24 hours in 6 divided doses. The methemoglobin was allowed to accumulate, and by the second day it had reached a value of 20 per cent of the total pigment, with a sulfanilamide concentration of the blood of $13.2 \mathrm{mgm}$. per cent. At this time, he was given intravenously $1.5 \mathrm{mgm}$. of methylene blue per $\mathrm{kgm}$. The cyanosis rapidly decreased and was no longer detectable after 30 minutes. Beginning with the next dose of sulfanilamide, he was then given one grain of methylene blue every 4 hours. Twenty hours later the methemoglobin concentration was 10 per cent. Two hours after this observation and one-half hour before opera- 
tion, the patient was again given methylene blue intravenously; the cyanosis which had recurred to a moderate extent again disappeared.

One dose of the drug was given after operation, then they were both discontinued for 12 hours, after which period the original dose of sulfanilamide was resumed, and the methylene blue was increased to 2 grains every 4 hours. During the rest of the period of observation, which covered 6 days, the observed methemoglobin concentration ranged from an undetectable amount to 8 per cent, with the sulfanilamide concentrations of the blood ranging from 6 to $16 \mathrm{mgm}$. per cent.

This child represents a case in which the administration of one grain of methylene blue every 4 hours was insufficient to prevent the reaccumulation of methemoglobin following its reduction after the intravenous administration of the dye, but in which 2 grains every 4 hours retarded considerably the rate of reaccumulation.

Case 6. Hazel B., an 11-year-old white girl, weighing $40 \mathrm{kgm}$., was admitted to the hospital with a diagnosis of postscarlatinal cervical adenitis. During the first 12 hours after admittance she received a total of 6 grams of sulfanilamide in 3 doses, and then was put on $\mathbf{0 . 2}$ gram per kgm. per 24 hours in 6 divided doses. Within 26 hours after the drug administration was started the methemoglobin concentration had reached a height of 27 per cent of the total pigment, the blood sulfanilamide being $13.9 \mathrm{mgm}$. per cent. At this time, she was given intravenously $1.5 \mathrm{mgm}$. of methylene blue per kilogram, and the methemoglobin concentration fell within $50 \mathrm{~min}$ utes to only 4 per cent of the total pigment. From this time, the patient was given 2 grains of methylene blue every 4 hours, and the methemoglobin concentration on this day remained below 6 per cent. On the next day, doses of both drugs were cut to one-half of the original, and the methemoglobin concentration rose to 14 per cent of the total pigment. The dose of methylene blue was then increased to 2 grains every 4 hours, after which the methemoglobin concentration showed a gradual decrease, finally falling to a level below 9 per cent, where it remained for 3 days.

This child showed an unusually high concentration of methemoglobin before the administration of methylene blue. The methemoglobinemia was almost completely eliminated by the intravenous administration of methylene blue, following which it was well controlled by 2 grains of methylene blue every 4 hours when the dose of sulfanilamide was 0.2 gram per $\mathrm{kgm}$. per 24 hours. However, when the doses of both drugs were cut in half, the methemoglobinemia promptly increased and was again controlled only when the methylene blue dose was put back to its original level.

\section{COMMENT}

From an earlier study of some of the toxic effects of sulfanilamide (12), and from clinical observations, we do not feel that the relief or prevention of methemoglobinemia alleviates any of the other toxic symptoms. The practical importance, therefore, of controlling methemoglobin accumulation and cyanosis rests upon certain other considerations. It would seem definitely undesirable to deprive an extremely ill patient of any considerable amount of the oxygen carrying capacity of the blood. We have shown that this deprivation may amount to as much as $\mathbf{3 7}$ per cent when moderately large doses of sulfanilamide are given, and such a reduction of oxygen carrying capacity would be extremely undesirable and perhaps dangerous in a patient with pulmonary disease, as pointed out by Bensley and Ross (13). Basman and Perley (10) have previously stated that when the oxygen capacity has dropped to a level equivalent to 8 grams of hemoglobin per $100 \mathrm{cc}$., they have considered it advisable either to discontinue the drug or reduce the dose, or to transfuse the patient. The ready conversion of methemoglobin back to hemoglobin by the use of methylene blue makes resort to such measures unnecessary, and much larger doses of sulfanilamide may be tried without limitations imposed by this factor. Even if oxygen want is not to be feared, the prevention of extreme cyanosis from the accumulation of methemoglobin is desirable in order to permit the recognition of possible cyanosis resulting from some other cause, and to make possible a better evaluation of the general clinical picture of the patient, which often appears deceptively alarming because of the methemoglobin cyanosis. Ordinarily, the oral administration of methylene blue will satisfactorily control the methemoglobinemia; but if this should become appreciable, it may, under certain circumstances, be desirable to reduce the concentration rapidly. This is particularly true in patients who must undergo anesthesia and operation. Effective reduction of methemoglobin may be readily accomplished, as has been shown, by the intravenous administration of methylene blue.

As a result of the experiences just described, the following dosages of methylene blue may be recommended. In general, for children weighing less than $20 \mathrm{kgm}$., 0.4 gram ( 6 grains) per day in 6 divided doses appears to be sufficient, at least for moderately large doses of sulfanilamide. For children weighing over $20 \mathrm{kgm}$., a similar dosage is usually effective if as little as 0.1 gram per $\mathrm{kgm}$. per day of sulfanilamide is 
being given. In these children, if more sulfanilamide is being administered, 0.8 gram of methylene blue in 6 divided doses is recommended. We feel that the accumulation of relatively small amounts of methemoglobin, up to 10 or 12 per cent of the total pigment, is of little consequence, certainly in patients who are not very ill. Therefore, the use of methylene blue in such patients does not seem indicated unless a degree of cyanosis, suggesting considerable accumulation of methemoglobin should develop, especially in view of the fact that the discoloration of the lips by the drug itself and of the bed-clothing by the urine and vomitus is, to say the least, objectionable.

As mentioned before, the accumulation of methemoglobin is not entirely proportional to the dosage of sulfanilamide, so that these amounts of methylene blue may, in a given case, have to be altered, but in general these are the doses which we have found effective. When we are giving the sulfanilamide orally, we prefer to distribute its administration over the entire 24 hours, usually in 6 divided doses, and the methylene blue is given with each dose of sulfanilamide.

No serious intoxications from the use of methylene blue in man have been reported. However, when the drug is given orally, even in moderate doses, it may cause vomiting and diarrhea; headache and tinnitus have also been reported (14). In spite of these effects, the drug may be considered only slightly toxic, and its continued use seems not to be harmful. During intravenous administration of the drug, care must be taken to avoid perivenous infiltration, which is markedly painful and may lead to necrosis.

Although no experimental data have been reported, from our clinical experience we feel that the simultaneous administration of methylene blue and sulfanilamide does not impair the therapeutic effectiveness of the latter.

\section{SUMMARY AND CONCLUSIONS}

A study was made of factors leading both to the accumulation and disappearance of methemoglobin in patients to whom sulfanilamide was administered, and the following conclusions were reached.

1. Reasonably close agreement exists between the direct spectroscopic determination of methe- moglobin and the determination of non-oxygen carrying hemoglobin.

2 . In the great majority of patients receiving 0.1 gram or more of sulfanilamide per $\mathrm{kgm}$. per 24 hours, cyanosis develops, and so far we have been able to demonstrate the presence of methemoglobin in every case of cyanosis.

3. There is marked individual variation in both the rate at which and the degree to which methemoglobin accumulates, although the dosage of sulfanilamide, its concentration in the blood, and perhaps also the extensiveness of the infection seem to have a direct relationship.

4. Methylene blue causes a very rapid disappearance of cyanosis with simultaneous reduction in methemoglobin concentration, when given intravenously in single doses of 1.0 to $2.0 \mathrm{mgm}$. per $\mathrm{kgm}$., or when given orally in doses of 1.0 to 2.0 grains (65 to $130 \mathrm{mgm}$.) repeated every 4 hours. The latter method also prevents any appreciable formation of methemoglobin if started simultaneously with sulfanilamide administration.

\section{BIBLIOGRAPHY}

1. Marshall, E. K., Jr., and Walzl, E. M., On the cyanosis from sulfanilamide. Bull. Johns Hopkins Hosp., 1937, 61, 140.

2. Peters, J. P., and Van Slyke, D. D., Quantitative Clinical Chemistry. Vol. II. Methods. Williams and Wilkins Co., Baltimore, 1932, p. 630.

3. Archer, H. E., and Discombe, G., Sulphaemoglobinemia: its cause and prevention, with special reference to treatment with sulphanilamide. Lancet, 1937, 2, 432.

4. Harrop, G. A., and Waterfield, Reginald L., Sulphemoglobinemia. J. A. M. A., 1930, 95, 647.

5. Paton, J. P. J., and Eaton, J. C., Sulphaemoglobinaemia and methaemoglobinaemia following administration of p-aminobenzenesulphonamide. Lancet, 1937, 1, 1159.

6. Hauschild, F., Die Wirkung des Katalysins (Thionin) bei der Methämoglobinvergiftung. Arch. $f$. exper. Path. u. Pharmakol., 1937, 184, 458.

7. Hauschild, F., Untersuchungen über die Wirkung einiger Redoxyfarbstoffe bei Züstanden gestörter Atmung. I. Katalysin (Thionin) und Methämoglobinvergiftung. Arch f. exper. Path. $u$. Pharmakol., 1936, 182, 118.

8. Wendel, W. B., Use of methylene blue in methemoglobinemia from sulfanilamide poisoning. J. A. M. A. (Correspondence), 1937, 109, 1216.

9. Peters, J. P., and Van Slyke, D. D., Quantitative Clinical Chemistry. Vol. I. Interpretations. Williams and Wilkins Co., Baltimore, 1931. 
10. Basman, J., and Perley, A. M., Report of patients treated with sulfanilamide at the St. Louis Children's Hospital. J. Pediat., 1937, 11, 212.

11. Marshall, E. K., Jr., Determination of sulfanilamide in blood and urine. Proc. Soc. Exper. Biol. and Med., 1937, 36, 422.

12. Hartmann, A. F., Perley, A. M., and Barnett, H. L., A study of some of the physiological effects of sulfanilamide. I. Changes in the acid base balance. J. Clin. Invest., 1938, 17, 465.

13. Bensley, E. H., and Ross, J. B., Methemoglobinemia due to sulphanilamide therapy. Canad. M. A. J., 1937, 37, 62.

14. Solis-Cohen, S., and Githens, T. S., Pharmacotherapeutics, Materia Medica and Drug Addiction. D. Appleton and Co., New York, 1928, p. 877. 